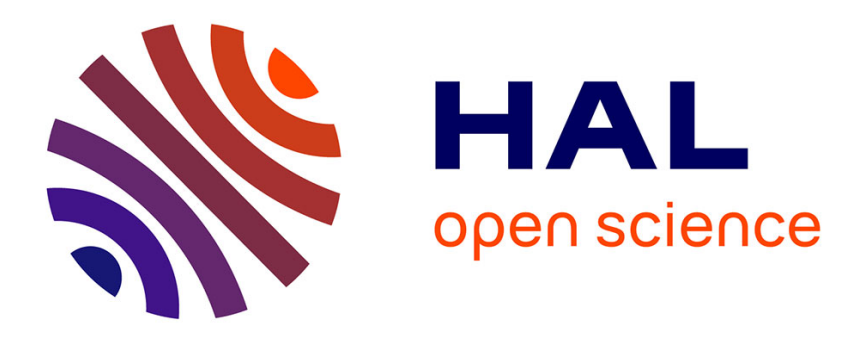

\title{
Extended three-dimensional digital image correlation (X3D-DIC)
}

Julien Réthoré, Jean-Philippe Tinnes, Stéphane Roux, Jean-Yves Buffiere, François Hild

\section{- To cite this version:}

Julien Réthoré, Jean-Philippe Tinnes, Stéphane Roux, Jean-Yves Buffiere, François Hild. Extended three-dimensional digital image correlation (X3D-DIC). Comptes Rendus Mécanique, 2008, 336, pp.643-649. 10.1016/j.crme.2008.06.006 . hal-00322190

\section{HAL Id: hal-00322190 https://hal.science/hal-00322190}

Submitted on 16 Sep 2008

HAL is a multi-disciplinary open access archive for the deposit and dissemination of scientific research documents, whether they are published or not. The documents may come from teaching and research institutions in France or abroad, or from public or private research centers.
L'archive ouverte pluridisciplinaire HAL, est destinée au dépôt et à la diffusion de documents scientifiques de niveau recherche, publiés ou non, émanant des établissements d'enseignement et de recherche français ou étrangers, des laboratoires publics ou privés. 


\title{
Extended three-dimensional digital image correlation (X3D-DIC)
}

\section{Corrélation d'images numériques tridimensionnelles étendue (CINÉ3D)}

\author{
Julien Réthoréa,b, Jean-Philippe Tinnes ${ }^{\mathrm{c}}$, Stéphane Roux ${ }^{\mathrm{a}}$, Jean-Yves Buffière ${ }^{\mathrm{c}}$, \\ François Hild ${ }^{\mathrm{a}}$ \\ ${ }^{a}$ LMT-Cachan, ENS de Cachan / CNRS UMR 8535 / Université Paris 6 / PRES UniverSud Paris \\ 61 Avenue du Président Wilson, F-94235 Cachan Cedex, France \\ ${ }^{\mathrm{b}}$ now at LaMCoS, INSA Lyon / CNRS UMR 5259, 18-20 rue des Sciences, F-69621 Villeurbanne Cedex, France \\ ${ }^{\mathrm{c}}$ MATEIS, INSA Lyon / CNRS UMR 5510, 7 Avenue Jean Capelle, F-69621 Villeurbanne Cedex, France
}

\begin{abstract}
A correlation algorithm is proposed to measure full three-dimensional displacement fields in a three-dimensional domain. The chosen kinematic basis for this measurement is based on continuous finite-element shape functions. It is furthermore proposed to account for the presence of strong discontinuities, similarly to extended finite element schemes, with a suited enrichment of the kinematics with discontinuities supported by a (crack) surface. An optimization of the surface geometry is proposed based on correlation residuals. The procedure is applied to analyze one loading cycle of a fatigue-cracked nodular graphite cast iron sample by using computed tomography pictures. Subvoxel crack openings are revealed and measured.

Résumé

Un algorithme de corrélation d'images numériques est présenté pour mesurer des champs de déplacement tridimensionnel avec des images à trois dimensions. La base cinématique choisie pour cette mesure est constituée de fonctions de forme (continues) d'éléments finis. Pour rendre compte de la présence de discontinuités fortes, à l'instar des schémas par éléments finis étendus, un enrichissement par une cinématique discontinue au travers d'une surface (fissurée) est implémenté. La géométrie de cette surface de discontinuité est optimisée en exploitant les résidus de corrélation. Cet algorithme est utilisé pour l'analyse d'un cycle de chargement d'une éprouvette de fonte à graphite sphéroïdal fissurée en fatigue à l'aide d'images tomographiques. Des ouvertures de fissures sensiblement inférieures à la taille du voxel peuvent être détectées et mesurées.
\end{abstract}

Key words: Rupture; Discontinuity; Photomechanics

Mots-clés : Rupture; Discontinuité; Photomécanique 


\section{Version française abrégée}

L'étude expérimentale d'échantillons fissurés repose habituellement sur des mesures photomécaniques en surface [1]. L'analyse d'images de tomographie aux rayons X constitue une voie intéressante pour caractériser également les effets tridimensionnels de la propagation de fissure et sa morphologie. Au-delà de la visualisation de la fissure elle-même et de son exploitation mécanique [2], la corrélation d'images numériques peut être appliquée sur des images 3D pour donner accès aux trois composantes du champ de déplacement dans l'ensemble du volume. Afin de résoudre le problème de l'identification d'un champ de déplacement minimisant l'écart entre un volume de référence (figure 1-a) et le volume déformé (figure 1-b) corrigé, une formulation globale sur l'ensemble du volume d'intérêt est adoptée. Moyennant l'utilisation d'une cinématique 3D enrichie [3], on accède à la mesure de la discontinuité du champ de déplacement sur la surface de la fissure. La détection de cette surface et son ajustement est un point important et le critère utilisé ici est basé sur la carte des résidus de corrélation. Un algorithme utilisant une transformation de Radon 3D [4] permet d'optimiser une fonction de niveau dont l'iso-zéro décrit la surface de la fissure.

Les performances de l'algorithme de corrélation sont caractérisées pour des images déformées artificiellement. L'enrichissement discontinu qui est implémenté permet d'utiliser des tailles d'élément importantes même dans le cas de cinématiques discontinues, et donc de conserver des niveaux d'incertitude faibles, un des avantages des techniques d'élements finis étendus appliquées à la corrélation d'images (figure 2).

Un échantillon de fonte à graphite sphéroïdal, préalablement fissuré en fatigue, a été imagé in situ à différents stades de chargement. Outre l'obtention de cartes de champs de déplacements discontinus tridimensionnels (figure 3), il est possible d'obtenir des résidus de corrélation (figure 4) dont les faibles valeurs indiquent un bon niveau de confiance dans les résultats obtenus qui permettent ici de caractériser des ouvertures de fissure résiduelles dues à des phénomènes de plasticité confinée (figure 5).

The experimental analysis of cracked samples or structures usually relies upon surface measurements by various photomechanical techniques [1]. With the use of 3D imaging techniques (e.g., computed tomography, magnetic resonance imaging), it is possible to obtain full 3D pictures of the in situ microstructure. Image analysis may already reveal from single images important morphological information about the $3 \mathrm{D}$ crack geometry, which may be coupled to a mechanical modeling [2]. Alternatively, the acquisition of a series of images obtained at different stages of a mechanical test opens the way for characterizing not only surface but also bulk phenomena. The resulting full displacement field allows for a very sensitive technique to detect crack geometries and opening fields with a resolution well below the voxel size.

The aim of the present Note is to show that the 3D kinematics introduced in the extended finite element method [3] may be used in a 3D correlation algorithm. When dealing with cracks, there is also a need for describing the crack surface. This is achieved by optimizing the zero-contour of a level set function thanks to the correlation residuals. Since 3D pictures are used, this technique is referred to as "eXtended 3D Digital Image Correlation" (or X3D-DIC), and corresponds to an extension of the X-DIC technique developed with $2 \mathrm{D}$ pictures [5].

Email addresses: julien.rethore@insa-lyon.fr (Julien Réthoré), stephane.roux@lmt.ens-cachan.fr (Stéphane Roux), jean-yves.buffiere@insa-lyon.fr (Jean-Yves Buffière), francois.hild@lmt.ens-cachan.fr (François Hild). 


\section{Extended 3D digital image correlation}

\subsection{Pictures}

$\mathrm{X}$-Ray microtomography enables one to get 3D pictures of the local density of solids exploiting the attenuation of a polychromatic X-ray beam. Image and/or volume correlations require a random texture to measure displacements. With the resolution of the acquisition device available at INSA Lyon, cast-iron samples were selected to provide adequate (random) markers. The graphite nodules, whose typical size is $50 \mu \mathrm{m}$, provide a random texture in the images (Figure 1) at the chosen magnification (i.e., the physical size of one voxel is equal to $13.5 \mu \mathrm{m}$ ). A testing machine inside the tomograph allows for taking 3D pictures of the specimen during a tensile test. A large sample was first cycled in a conventional servohydraulic testing machine to grow a fatigue crack. It was subsequently machined so that the gauge volume has a length of $4 \mathrm{~mm}$ and a square cross-section of $2 \times 2 \mathrm{~mm}^{2}$. The crack is visible on the deformed picture of the specimen (Figure 1). The dynamic range of the reconstructed pictures is equal to 16 bits. Only a
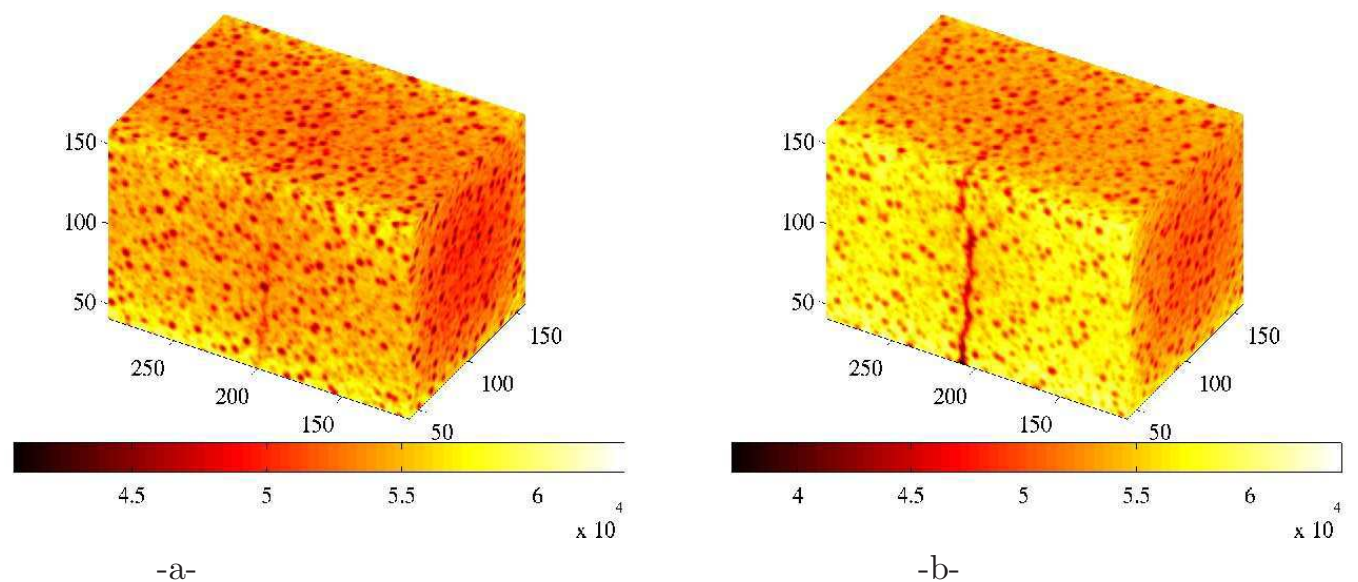

Figure 1. Reference (a, load $20 \mathrm{~N})$ and deformed (b, load $400 \mathrm{~N}) 3 \mathrm{D}$ images of a cracked sample $(180 \times 120 \times 120$ voxels, 16-bit digitization). The load is applied along the longitudinal direction (normal to the crack). Images de référence (a, $20 \mathrm{~N}$ ) et déformée $(b, 400 \mathrm{~N})$ d'un échantillon fissuré $(180 \times 120 \times 120$ voxels, codage sur 16 bits). L'effort est appliqué dans la direction longitudinale (normale à la fissure).

part of the picture $(180 \times 120 \times 120$ voxels $)$ will be analyzed in the sequel by using a standard personal computer.

\subsection{Enriched kinematics}

To capture the displacement discontinuity across crack faces, a 3D enriched finite element kinematics is chosen [3] for the measured displacement field $\mathbf{u}$

$$
\mathbf{u}(\mathbf{x})=\sum_{n \in \mathcal{N}, \alpha} a_{\alpha n} N_{n}(\mathbf{x}) \mathbf{e}_{\alpha}+\sum_{n \in \mathcal{N}_{e n r}, \alpha} d_{\alpha n} N_{n}(\mathbf{x}) \mathrm{F}_{n}(\mathbf{x}) \mathbf{e}_{\alpha}
$$

where $\mathbf{x}$ is the local (voxel) coordinate, $\mathrm{F}_{n}$ the enrichment functions, and $\mathcal{N}_{\text {enr }}$ is a sub-set of $\mathcal{N}$ in which nodes hold enriched degrees of freedom $d_{\alpha n}$. In the following, the simplest shape functions $N_{n}$ are implemented, namely, trilinear polynomials associated with 8-node cube elements (or C8). The enriched 
kinematics $\mathrm{F}_{n}$ is introduced by exploiting the partition of unity [6] property of finite element shape functions, namely, for all $\mathbf{x}, \sum_{n \in \mathcal{N}} N_{n}(\mathbf{x})=1$. The following definition holds for the enrichment functions

$$
\mathrm{F}_{n}(\mathbf{x})=\mathcal{H}(\mathbf{x})-\mathcal{H}\left(\mathbf{x}_{n}\right)
$$

where $\mathbf{x}_{n}$ is the the position of node $n$ [7] and the function $\mathcal{H}$ is equal to 1 above the crack surface and 0 below. It is conveniently implemented from the level set field $\phi(\mathbf{x})$ that gives the signed distance to the crack surface. The function $\mathcal{H}(\mathbf{x})$ then reduces to the Heaviside function $H$ of the level set. Only nodes whose support is cut by the surface hold enriched degrees of freedom. In the present case, the crack front is not detected on the surface and the support of the discontinuity traverses the entire specimen. By adopting the previous discretization scheme of the displacement field, the latter is rewritten for all points $\mathbf{x}$ as

$$
\mathbf{u}(\mathbf{x})=[\Psi(\mathbf{x})]\{\mathbf{U}\}
$$

where $[\Psi]$ is a row vector containing the values of all the interpolation functions $\Psi_{m}$, and $\{\mathbf{U}\}$ the column vector of the unknown (standard and enriched) degrees of freedom.

\subsection{Correlation algorithm}

By using the previous displacement basis, the passive advection of the texture between the reference $f$ and the deformed $g$ images (e.g., see Figure 1) reads

$$
g(\mathbf{x})=f(\mathbf{x}+\mathbf{u}(\mathbf{x}))
$$

From the knowledge of $f$ and $g$, the measurement problem consists in identifying $\mathbf{u}$ as accurately as possible. To estimate $\mathbf{u}$, the quadratic difference, $\varphi^{2}=[g(\mathbf{x})-f(\mathbf{x}+\mathbf{u}(\mathbf{x}))]^{2}$ is integrated over the studied domain $\Omega$

$$
\Phi^{2}=\int_{\Omega} \varphi^{2} \mathrm{~d} \mathbf{x}
$$

This functional is minimized with respect to the set of unknown degrees of freedom (i.e., $a_{\alpha n}$ and $d_{\alpha n}$ ). This procedure is performed through successive low-pass filtering of the images (from coarse to fine) and first order expansion of $\varphi[\delta \mathbf{u}]=g(\mathbf{x})-f\left(\mathbf{x}+\mathbf{u}^{(n)}(\mathbf{x})\right)-\nabla f\left(\mathbf{x}+\mathbf{u}^{(n)}(\mathbf{x})\right) \delta \mathbf{u}$ about already resolved displacements $\mathbf{u}^{(n)}$ so that each iteration is a simple linear problem in the incremental correction $\delta \mathbf{u}$. The method proposed herein is therefore a Galerkin approach to image correlation. In a matrix-vector setting, the linear system to solve globally over the whole region of interest $\Omega$ reads

$$
[\mathbf{M}]^{i}\{\delta \mathbf{U}\}-\{\mathbf{b}\}^{i}=\mathbf{0}
$$

with

$$
M_{n m}^{i}=\iint_{\Omega}\left(\Psi_{n}(\mathbf{x}) \cdot \nabla f\left(\mathbf{x}+[\Psi(\mathbf{x})]\{\mathbf{U}\}^{i}\right)\right)\left(\Psi_{m}(\mathbf{x}) \cdot \nabla f\left(\mathbf{x}+[\Psi(\mathbf{x})]\{\mathbf{U}\}^{i}\right)\right) \mathrm{d} \mathbf{x}
$$

and

$$
b_{n}^{i}=\iint_{\Omega}\left(\Psi_{n}(\mathbf{x}) \cdot \nabla f\left(\mathbf{x}+[\Psi(\mathbf{x})]\{\mathbf{U}\}^{i}\right)\right)\left(g(\mathbf{x})-f\left(\mathbf{x}+[\Psi(\mathbf{x})]\{\mathbf{U}\}^{i}\right)\right) \mathrm{d} \mathbf{x}
$$

where $\{\delta \mathbf{U}\}$ is the incremental correction vector. One key aspect of the displacement field in the presence of cracks is the shape of the crack surface. The latter is described by the zero-contour of a level set. To position the latter, a first correlation evaluation is performed without enriched kinematics $\left(d_{\alpha n}=0\right)$, referred to as $\mathrm{C} 8$. The residual map $\varphi$, which is evaluated for each voxel, is used to detect the crack face. By considering small volumes (e.g., $4^{3}$ voxels) containing the zone where the residuals are the highest (i.e., where an enrichment is needed), the corresponding elementary residual is Radon transformed to determine the local tangent plane to the crack face. When the crack face level set is initialized, an enriched kinematics is sought (i.e., $d_{\alpha n} \neq 0$ ), which is referred to as $\mathrm{X}-\mathrm{C} 8$. 
It is worth noting that this detection algorithm does not require the crack opening to be greater than one voxel. In this sense, it is much better suited for our purpose than other segmentation techniques which could have been considered (see e.g., Ref. [8]). Moreover it allows for iterative adjustments of the surface geometry within the same framework.

\subsection{Performances}

Before performing a correlation on the two pictures of Figure 1, it is worth analyzing the performance of the correlation algorithm. A common baseline analysis consists in prescribing known displacements to the reference picture and evaluate the displacement uncertainty. Two cases are considered. First, a uniform displacement ranging from 0 to 1 pixel is prescribed. This allows one to estimate both the systematic and fluctuating parts of the error in the measured displacement. The fluctuation part is typically much larger than the bias. Thus, only the latter is documented herein and quantified through the standard deviation of the displacement field. It is shown for both C8 and X-C8 algorithms in Figure 2-a. Even though the kinematic basis of the extended algorithm is richer than in the $\mathrm{C} 8$ version, the overall performance is conserved. It levels off similarly to the C8 algorithm, yet at the (low) value of about $2 \times 10^{-2}$ voxel. To capture without enrichment a rapid variation of the displacement such as a discontinuity, a small element size would be needed, thus implying a rather large uncertainty. Conversely, with enrichments, the full benefit of the very small uncertainty attached to large element sizes is preserved without any prejudice to the description of the discontinuity. This result is shown in Figure 2-b for the displacement field, and for the displacement jump in Figure 2-c. This analysis shows the benefit of resorting to enriched kinematics
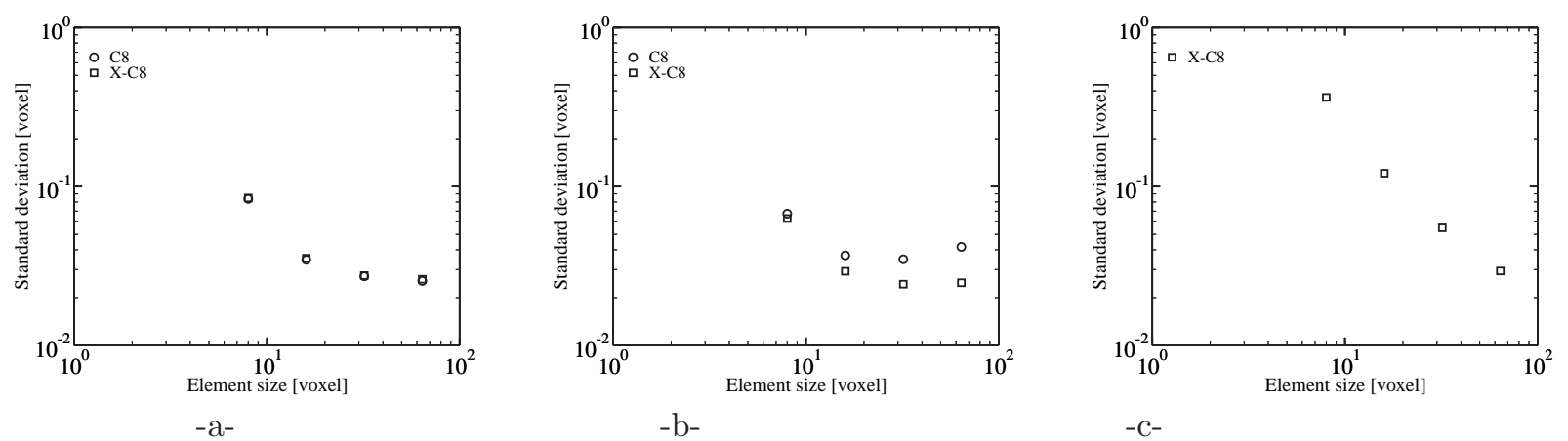

Figure 2. Displacement field uncertainties as functions of the element size for $\mathrm{C} 8$ and extended (X-C8) algorithms when a uniform displacement is prescribed (a), or a discontinuous displacement (b). -c- Displacement jump uncertainty when a discontinuous displacement is prescribed. Incertitudes en déplacement en fonction de la taille des éléments pour un algorithme C8 et X-C8 lorsqu'un champ constant (a) ou discontinu (b) est imposé. -c- Incertitude en saut de déplacement lorsqu'un champ discontinu est imposé.

when one wants to capture displacement discontinuities on a coarse mesh (i.e., the basic idea of extended finite element procedures).

\section{Example}

The displacement field obtained in the direction of the loading axis is shown in Figure 3. Elements of size $16 \times 16 \times 16$ voxels are considered. The displacement map over the entire volume of interest is shown together with the values of the displacement jump over the crack faces on the detected crack geometry. 
Displacement jumps of the order of 1.5 voxel $(1$ voxel $=13.5 \mu \mathrm{m})$ are obtained at one of the corners of the crack, while the sample face average crack opening (i.e., discontinuity of the displacement component normal to the crack surface) is of the order of one voxel. Note however, that as one progresses along the crack towards its front, an opening of 0.1 voxel is resolved.
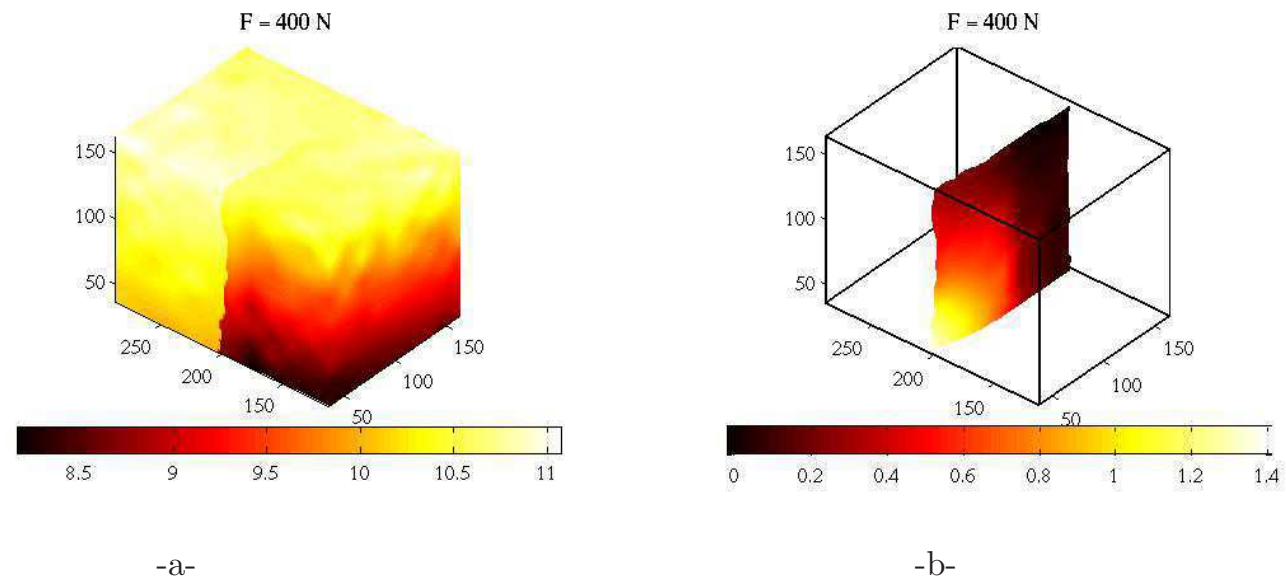

Figure 3. Displacement field (a) and displacement jump (b) along the loading axis (normal to the crack orientation) expressed in voxels $(1$ voxel $=13.5 \mu \mathrm{m})$ when the two 3D pictures of Figure 1 are considered. Champs de déplacement (a) et de saut de déplacement (normal à la fissure) exprimés en voxels (1 voxel $=13.5 \mu \mathrm{m}$ ) pour l'analyse des deux images de la figure 1.

Figure 4 illustrates the enrichment procedure on the analyzed pictures. First, a calculation with no enrichment is performed and yields the correlation residuals $\varphi$ that are computed for each voxel $\mathbf{x}$ (Figure 4a). For illustration purposes, the residuals are thresholded. When the proposed optimization procedure is followed, the corresponding residuals are shown in Figure 4b on the crack surface. The average value of $\varphi$ over the entire volume of interest is $1.8 \%$ of the dynamic range of the reference image, except on the crack faces themselves where the average residual is $2.6 \%$. The residuals are very small, thereby proving that the displacement estimate is likely to be trustworthy.

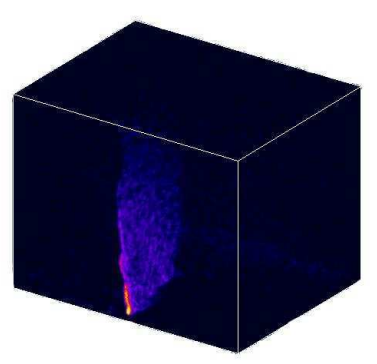

$-a-$

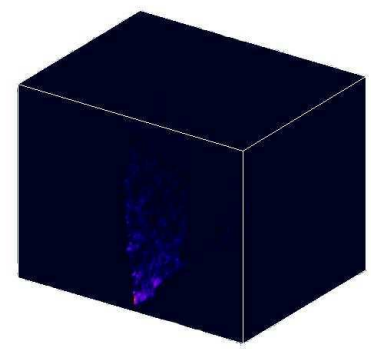

-b-

Figure 4. Thresholded correlation residuals prior to (a) and after (b) enriching the measurement basis. Résidus de corrélation seuillés avant (a) et après (b) enrichissement de la base de mesure.

Last, Figure 5 shows the crack opening fields (i.e., the crack opening value supported by the crack surface) for four different applied load levels. First, when the applied load is equal to $100 \mathrm{~N}$, no opening is measured since the displacement jump levels are very close to the uncertainties (Figure 2c). Second for a load of $200 \mathrm{~N}$, there is a significant opening that becomes even more important when the maximum load 
level $(400 \mathrm{~N})$ is reached. When the sample is subsequently unloaded $(20 \mathrm{~N})$, a residual crack opening is observed.
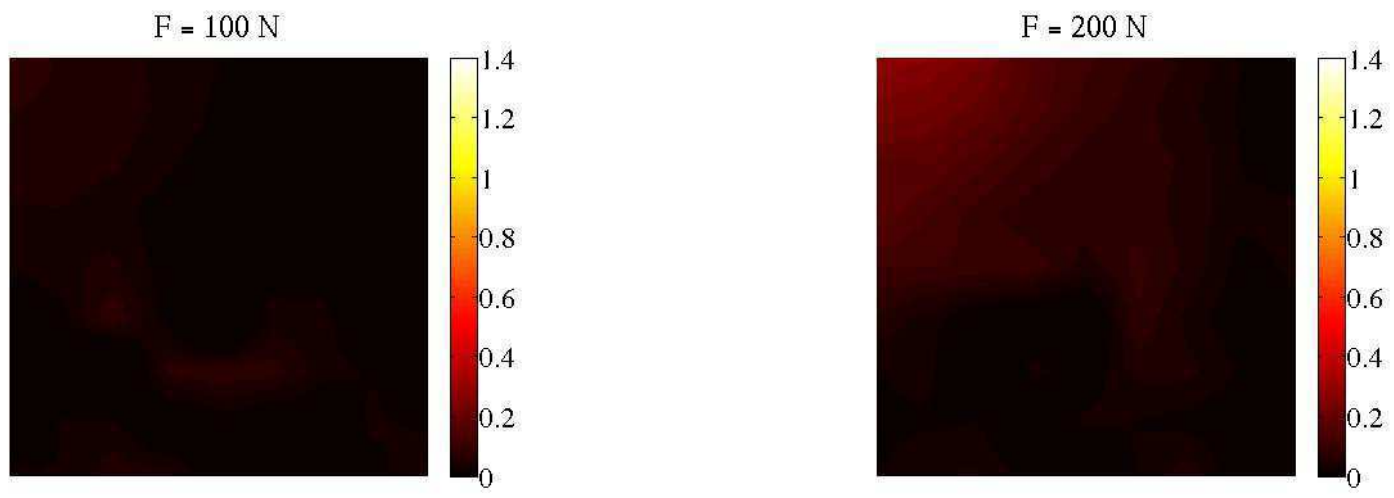

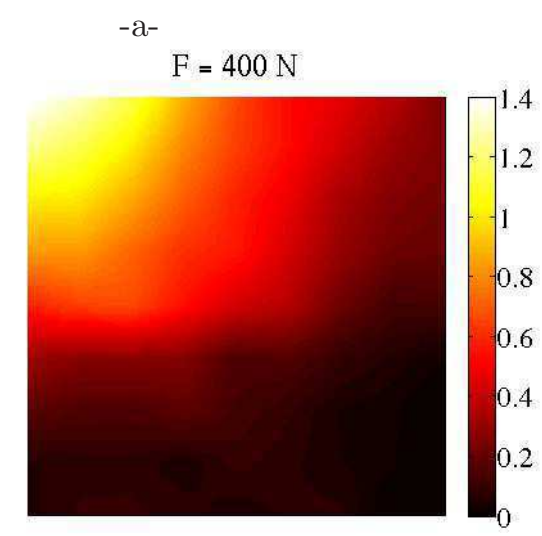

$-\mathrm{c}-$

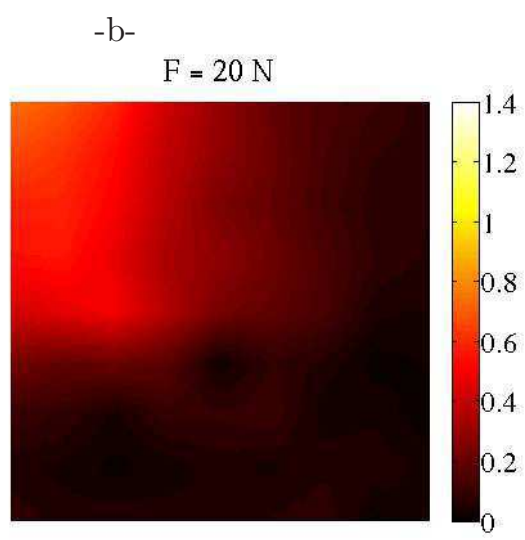

$-\mathrm{d}-$

Figure 5. Crack opening displacements along the loading axis (normal to the crack orientation) expressed in voxel $(1$ voxel $=13.5 \mu \mathrm{m}$ ) for four different load levels: $100 \mathrm{~N}$ (a), $200 \mathrm{~N}$ (b), $400 \mathrm{~N}$ (c) and $20 \mathrm{~N}$ (d). Champs d'ouverture normale à la fissure exprimés en voxel $(1$ voxel $=13.5 \mu \mathrm{m})$ pour différents niveaux de chargement : $100 \mathrm{~N}(\mathrm{a}), 200 \mathrm{~N}(\mathrm{~b})$, $400 N(c)$ et $20 N(d)$.

\section{Summary and perspectives}

The present technique of 3D image correlation allows for the measurement of 3D displacement fields in the presence of cracks. It opens the way to a study of fatigue crack propagation based on an in-depth determination of the crack geometry. Moreover, stress intensity factors along the crack front may be evaluated by post-processing the measured data, provided the crack front is localized (by another level set). Under cyclic loadings, such a tool may clarify the role of partial crack closure induced by crack tip 
plasticity, not only from a global examination, or free surface investigations, but in the entire sample volume.

\section{Acknowledgements}

This work is part of a project (PROPAVANFIS) funded by the CETIM foundation.

\section{References}

[1] P. K. Rastogi, edt., Photomechanics, (Springer, Berlin (Germany), 2000), 77.

[2] E. Ferrié, J.-Y. Buffière, W. Ludwig, A. Gravouil and L. Edwards, Three-dimensional study fof fatigue crack propagation of a semi-elliptical crack: 3D crack visualization using X-ray microtomography and numerical simulation of crack propagation using the Extended Finite Element method, Acta Mat. 54 [4] (2006) 1111-1122.

[3] N. Moës, A. Gravouil and T. Belytschko, Non-planar 3D crack growth by the extended finite element and level sets. Part I: Mechanical model, Int. J. Num. Meth. Eng. 53 [11] (2002) 2549-2568.

[4] H. Barrett, The Radon transform and its applications, in: Progress in Optics (North-Holland, Amsterdam, The Netherlands, 1984), 217-286.

[5] J. Réthoré, S. Roux and F. Hild, From pictures to extended finite elements: Extended digital image correlation (X-DIC), C. R. Mécanique 335 (2007) 131-137.

[6] I. Babuska and J. M. Melenk, The partition of unity method, Int. J. Num. Meth. Eng. 40 [4] (1997) 727-758.

[7] G. Zi and T. Belytschko, New crack-tip elements for XFEM and applications to cohesive cracks, Int. J. Num. Meth. Eng. 57 [15] (2003) 2221-2240.

[8] B. Bourdin and A. Chambolle, Implementation of an adaptive finite-element approximation of the Mumford-Shah functional, Num. Math. 85 (2000) 609-646. 